\title{
FREEk! \& La Mota Ediciones \\ o cómo ser editor y algo más y no morir en el intento
}

\author{
Tali Carreto
}

$C$ orría abril del año pasado. Miqui Puig, con nuevo disco bajo el brazo, también hacía otro tanto en nuestra primera portada. La primera imagen que todos tuvimos de FREEk!: un tipo gordito, con una sudadera y unos vaqueros, corriendo por el parque. Más freak imposible. Empezábamos con buen pie.

Pero, żqué hubo antes de las zancadas de Miqui?

Buena pregunta. Algo que también habría después: mucho trabajo. $\mathrm{Ni}$ por asomo -o tal vez sí, pero no queríamos creerlo- pensamos en la cantidad de sudor ingente que provoca una publicación mensual. Y gratuita. Pero vayamos por partes...

\section{Pasitos de bebé}

Los tres responsables de La Mota Ediciones, que así se llama la mamá de FREEk!, procedíamos de una experiencia común. Los tres -César Guisado, ahora responsable de Publicidad, Jesús, su hermano y diseñador de La Mota, y un servidor, Tali Carreto, coordinador de Redacción de FREEk!- habíamos estado, en mayor o menor medida, involucrados en otra publicación de distribución gratuita. Pero el hecho de no comandar la nave y contemplar impotente cómo hacía aguas nos hizo abandonar el barco. Y así, tras unos meses de dialéctica mental y encrucijadas vitales, decidimos poner en funcionamiento una empresa por cuenta y riesgo propios. 
Nada más comenzar la andadura nos dimos de bruces con la realidad. El pequeño y mediano empresario, joven y ajeno al sector servicios, lo tiene bien chungo a este lado de Europa. Al menos, para comenzar. Cero ayudas inmediatas, cero créditos, cero confianza. Así que, algo cortos pero nada perezosos, cada uno de los tres nos abocamos a un préstamo personal con la pertinente entidad bancaria con el fin de tener algo de

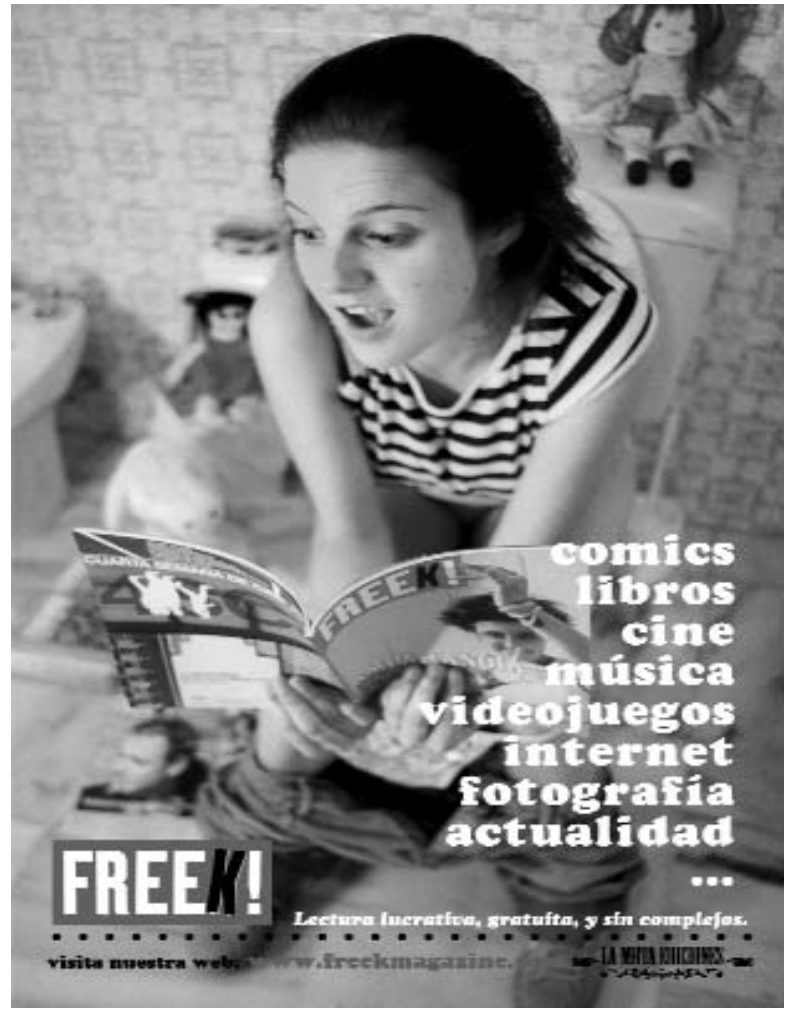
caja para empezar a andar... iBienvenida seas, vida de adulto!

Mientras ultimábamos los requisitos con el banco, gracias al Ayuntamiento de Sevilla conseguimos arañar una pequeña subvención, que al fin se hizo realidad hace unos meses. El problema que tiene una empresa como la nuestra a la hora de las subvenciones es que casi todas las ayudas valoran el gasto inicial en inversión. El nuestro, como podrán suponer, es bastante escaso, ya que el gasto real de una revista radica en su tirada mensual, que te obliga a desembolsar un suculento fajo de billetes cada principio de mes. La inversión inicial, ordenadores aparte, deja bastante que desear. Pero lay, ese mes a mes que seca nuestras arcas hasta el borde de la anemia!

Pero dejemos llantos a un lado. Actualmente estamos a la espera de una segunda subvención, obra y gracia del SAE (o Servicio Andaluz de Empleo), que supondrá al fin una inyección de adrenalina traducida en lerus, que diría Paco el de Alcalá.

Pero mientras llegaban las resoluciones y nos amparábamos en una confianza ciega en nuestros planes de empresa -planes reales, ojo, supervisados por la Escuela de Empresas sita en Sevilla-, la revista comenzaba a andar. 


\section{La niña no está sola}

Algo más teníamos claro sobre FREEk!, nuestra revista. $O$ varias cosas, para ser sinceros:

1) Que no sería, jamás, otro escaparate vacuo de tendencias, "otro hipermercado de modernidad en temporada de rebajas", como decíamos en nuestra primera editorial.

2) Que intentaríamos entregar mes a mes un producto serio, a pesar de estar bañado de humor de principio a fin.

3) Que nuestra revista, aunque fuera la niña de nuestros ojos, no sería nuestra única tarea.

Las dos primeras cuestiones las creemos ya solventadas. Nuestra línea editorial, clara y definida desde aquel primer número, continua firme. Humor y erudición a partes iguales. Escapar de lugares comunes y huir de los mismos contenidos vistos en mil y una revistas, ofreciendo al público otras perspectivas, otros personajes, otros protagonistas. No hablar sólo del presente, sino echar también un vistazo al pasado. Y, sobre todo, saber a ciencia cierta que el lector, tú, por ejemplo, no es un completo idio-

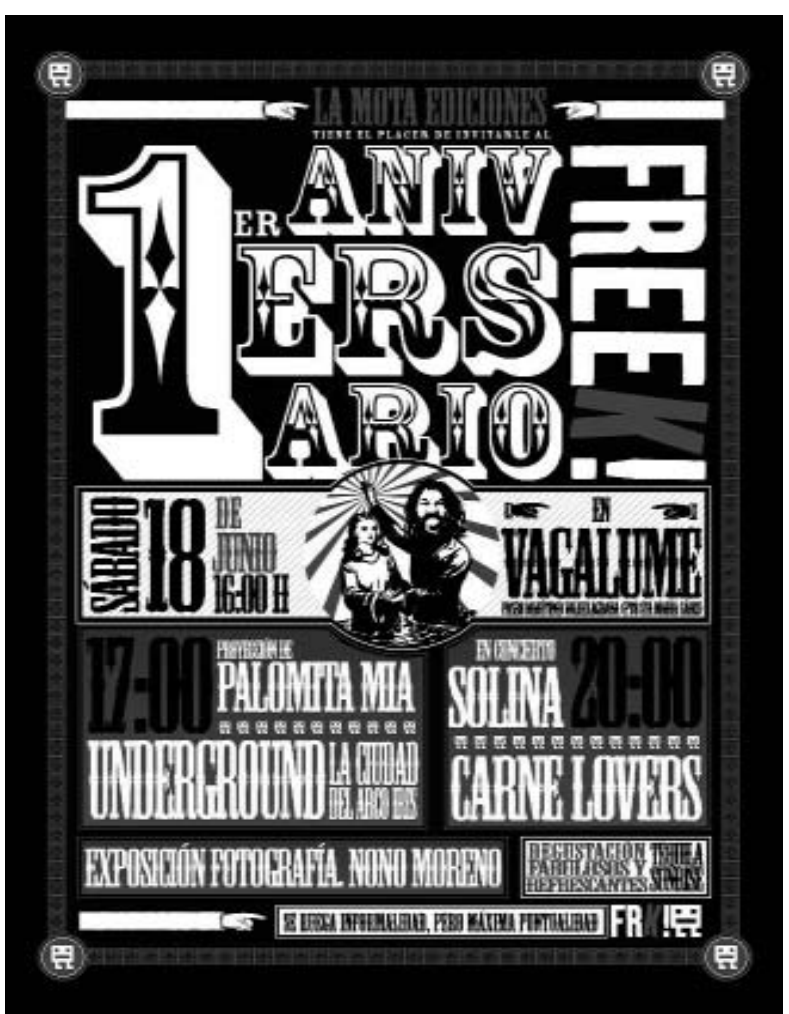
ta. Ésas fueron las premisas con las que creamos FREEk! Y con ellas seguimos. A pesar de ligeros cambios e inminentes remodelaciones, el espíritu sigue y seguirá imbatible.

La tercera cuestión tiene más enjudia. Quien crea que puede vivir en el estado actual de las cosas a costa de una publicación gratuita con menos de dos años de edad, que venga aquí y nos cuente cómo lograrlo. Seremos todo oídos. A sabiendas que los beneficios de una revista gratuita, aun con tirada holgada (15.000 ejemplares) en Madrid y Andalucía, tardarían lo suyo en aparecer, nuestra primera intención fue siempre diversificar las tareas de La Mota Ediciones en 
todas aquellas direcciones que nos fuera posible.

La Mota realiza trabajos de publicidad, diseño y comunicación para pequeñas, medianas y grandes empresas. Una vez asentada la distribución de nuestra revista, decidimos dedicar tiempo también a esta serie de labores. Y así, desde hace unos meses, ya hemos realizado estas tareas para clientes de lo más dispar: restaurantes como La Dehesa del Conde o Vagalume, pubs como Wind o El Hoyo, madereras como Wood Dreams, ase-

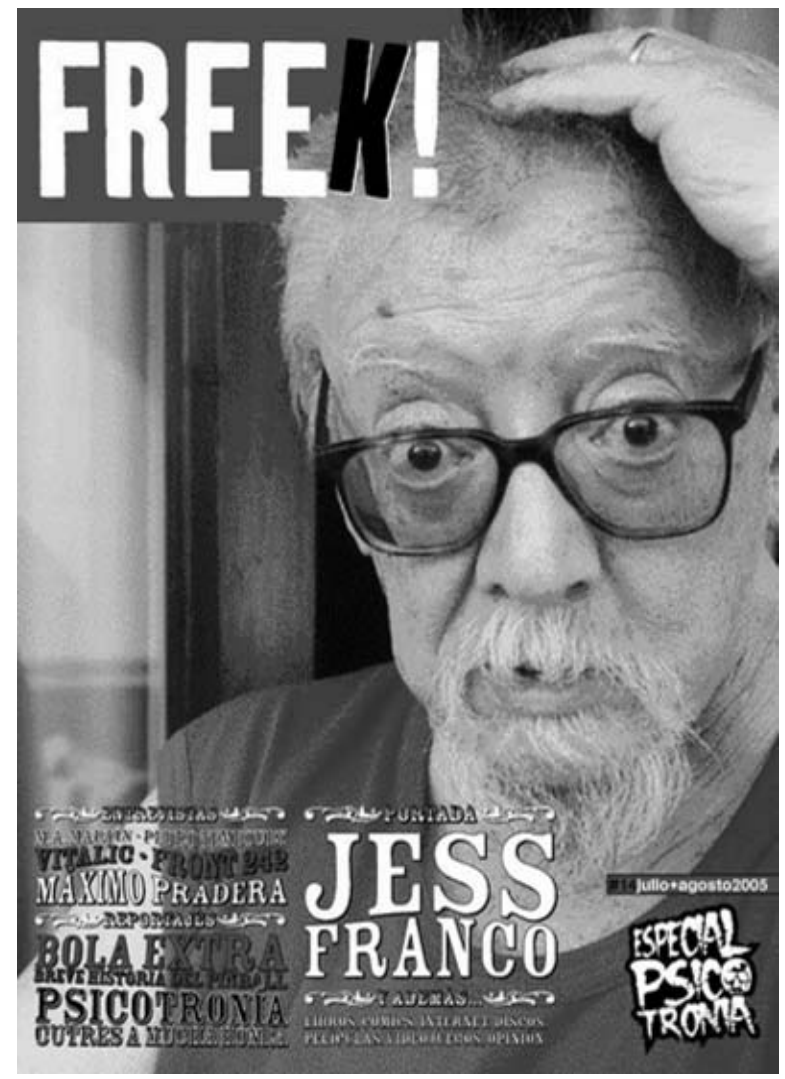
sores como Acsi y asociaciones como CARDIJN. Y dada la eficacia de nuestra labor y la satisfacción de nuestros clientes, parece que va a haber diseños La Mota para rato...

$Y$ mientras, alrededor de FREEk!, se vertebra todo, ya que se erige como una carta de presentación inmejorable. Las empresas, ya sean clientes o con posibilidades de serlo, también conocen gracias a la revista que ofertamos otras labores. A veces, incluso, la oferta comprende dos o más de nuestras acciones. Por ejemplo, a un mismo cliente le podemos realizar una campaña de promoción en medios, el diseño de su logo, cartelería e imagen corporativa e incluir un espacio de publicidad en nuestra revista. Y todo a un precio asequible, ya que al tratarse de una misma empresa abaratamos costes. Si tienes algo que anunciar, somos tu solución. No lo dudes.

\section{La hora del balance}

Han pasado 17 meses desde aquel abril, aquél con Miqui Puig a la carrera. Y llegaron otros tantos números de FREEk!, siempre puntuales a su cita. El cine, la música, los libros, los comics... son tantos los que nos han acompañado, que un breve repaso tan sólo nos daría una somera idea del esfuerzo re- 
alizado y la ilusión depositada. Las entregas a última hora, tantas noches sin pegar ojo. Y tantas cosas por vez primera: la primera portada internacional, nuestra primera oficina (ique empezamos en casa de los padres de los hermanos Guisado, chicos!), los primeros descubiertos, los primeros talones... Y tantos amigos. Por nuestras páginas, que son también las vuestras, han desfilado personajes nacionales como Pablo Carbonell, Javier Ruibal, Benito Zambrano, Jess Franco, Kiko Veneno, Juan Tamariz, Faemino \& Cansado, Nawja Nimri, Paul Naschy, Andreu Buenafuente y Francisco lbáñez.

Y también artistas internacionales de la talla de Morgan Freeman, Win Wenders, Leo Bassi, Can, Jonathan Richman, Donovan, Harvey Pekar o Ron Jeremy.

Pero esos son los nombres conocidos, los titulares.

Detrás, hay todo un equipo de personas que jamás baja de la treintena, entre redactores, fotógrafos e ilustradores. Diseminados por aquí, por

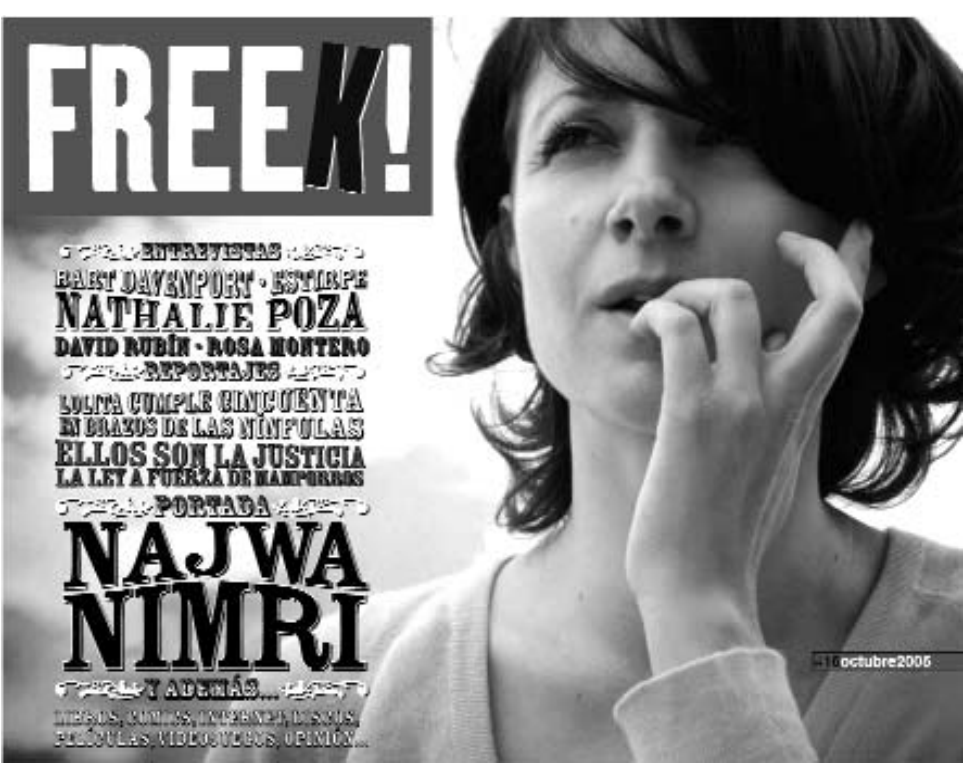
allá e incluso el más allá, nuestros colaboradores son el pedestal sobre el que se eleva esa columna vertebral que es FREEk!

Desde aquí, y sin necesidad de dar más nombres propios (†odos sabemos que la mala memoria es nula consejera), aprovechamos estas líneas para dar las gracias a todos aquellos que nos han apoyado desde el principio. Sin vosotros, este sueño no hubiera sido posible.

¿La hora del balance? ¿̇ué tal dentro de un tiempo? Mientras tanto, seguiremos soñando. Con los ojos bien abiertos. 